\title{
Homogenous Charge Compression Ignition (HCCI) combustion control by controlling the CNG parameters
}

\author{
S.Vignesh Eswaran ${ }^{1}$, Dr. P.Naveen Chandran ${ }^{2}$ \\ \{isbar2807@gmail.com ${ }^{1}$, asiriyan@gmail.com² $\}$
}

Research scholar, Bharath Institute of Higher Education and Research, Chennai ${ }^{1}$, Professor of Automobile Dept., Bharath Institute of Higher Education and Research, Chennai ${ }^{2}$

\begin{abstract}
Homogenous Charge Compression Ignition (HCCI) is a incineration manner that produces actual small nitrogen oxides has high thermal performance. it's far one few answers reachable appears very auspicious to address the concerns at the atmospheric air pollution and depleting fossil fuel assets aggravated with the aid of growing electricity intake of the arena. but, presently there is no set up method HCCI incineration controller and it has high $\mathrm{HC}$ and $\mathrm{CO}$ emissions. This paper, CNG straight injection became suggested as a tool for HCCI combustion manage. Section of fuel and CNG pour prices and diploma of stratification of CNG have been recognized as ability parameter for HCCI combustion manipulate. role of CNG straight injection on HCCI incineration manage and consistent consequences on presentation and emission traits have been experimentally examined. Sizes of fuel and CNG and degree of stratification of CNG have been observed actual method of incineration manage within sure restrictions of engine load and $\mathrm{CO}$ and $\mathrm{HC}$ releases can be drastically decreased. It become determined that warmth released by means of gasoline HCCI combustion occasioned within the following incineration of $\mathrm{CNG}$ engine load can accelerated using various CNG injection charge..
\end{abstract}

Keywords: HCCI Combustion control, CNG Parameters, engine load, air pollution control.

\section{Introduction}

The innovation of motor is a significant achievement in the transport of materials and man and it prompted a stupendous jump in the financial advancement of individuals of this earth. Notwithstanding, when it was presented the fundamental specialized contemplations for the plan of the motors were to fill the need of transport with great burden conveying limits at higher paces. The effectiveness of energy change and the outflow attributes of a motor were of smallest importance for the general public of car architects and fashioners.

Albeit world energy utilization got the petroleum products plummeted altogether 2009 interestingly after 1981 because of the monetary emergency, it is accounted for that it would arrive at a lot more significant levels in 2035 because of the fast financial improvements in specific districts of the world [1].

Use of energy utilizing the right now accessible innovations brings about emanation of hurtful poisons and ozone harming substances that bring about an unnatural weather change and disintegrated nature of environmental air. The inside burning motor, the most generally 
utilized sort of motor for car applications, utilizes airborne as functioning average and as a wellspring of oxygen ignition of fuel[2]. The system of transformation of warmth into effort begins with the freedom of warmth energy limited in the fuel by the ignition cycle. The cycle of ignition is perplexing with many transitional substance responses including a few segments fuel. Burning creates hurtful gas side-effects regularly framed particularly because of deficient compound responses. A portion of the significant poisons produced motors are oxides of carbon, sulfur oxides, oxides of nitrogen, and hydro-carbons actual fuels. This additional significant subject seems confine utilization IC motors later on [3].

In this paper, another methodology is suggested for regulatory double fuels HCCI burning. The methodology mix changing extents of gas and CNG shifting the level of CNG delineation gas air combination.

\section{Related Works}

The HCCI ignition can measure up to the hot bulb motors [4] created in the beginning phases of advancement of inward burning motor. The hot bulb motors utilized a helper chamber that could be remotely warmed for startup. The fuel was infused into the entry that associated the warmed cavity and the primary burning cavity. As the fuel was infused throughout the initial piece of the pressure hit, it had sufficient opportunity to get blended in with the air in the wake of being disintegrated by the exteriors of the warm bulb. This brought about the development of same custody in the chamber and the motor was working on the burning with same custody and auto start.

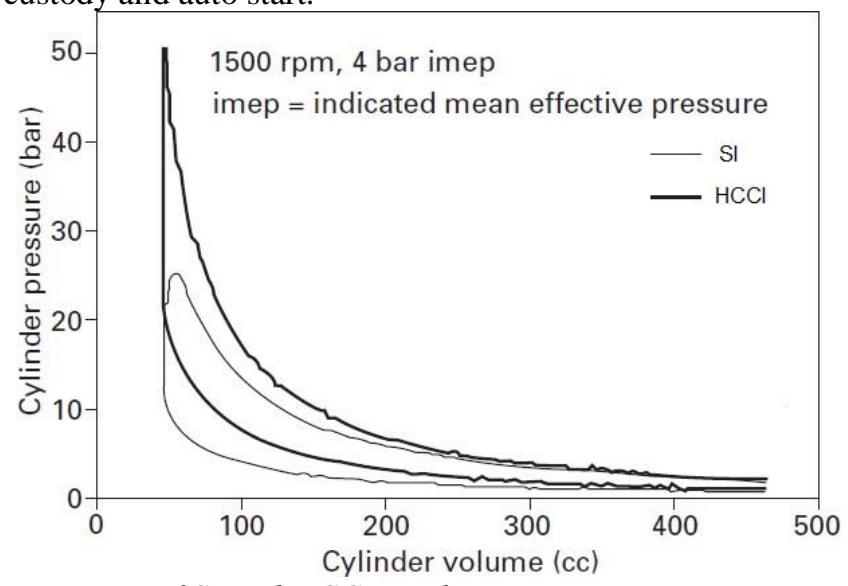

Fig 2.1 Pressure traces of SI and HCCI combustion at same operating conditions [14].

Fig 2.1 demonstrations distinctions weight increase paces HCCI and SI ignition similar motor speed and burden [14]. The pressing factor increase level because of some technique for ignition is restricted to $10 \mathrm{CAD} /$ bar by the material presently utilized for structure the motors [15]. To restrict the high warmth discharge rate and keep away from auto start at an initial case throughout pressure blow, the motor must be worked with very lean blends. Similar diesel motors, HCCI motor is worked at totally open choke and heap on a HCCI motor is encountered by expanding fuel fixation noticeable all around. Since the HCCI motor must be 
worked at far more slender than the stoichiometric disorder to oversee high warmth discharge rates, the heap range that can be taken care of is exceptionally restricted when contrasted with motors of similar size working on SI or CI burning. All in all, the greatest burden treatable with HCCI burning is low, regularly dwindling inside $30 \%$ of the pinnacle force or IMEP achieved SI or CI ignition [16].

\section{Methodology}

\section{Dual Fuel HCCI Combustion}

The motor utilized for this exploratory investigation houses the fuel arrangement of straight infusion of compacted flammable gas $(\mathrm{CNG})$ or a vaporous fuels and great pressure proportion reasonable for activity $\mathrm{CNG}$ fuel flash start. This motor, momentarily referenced as CNG DI Engine theory from now on, is a solitary chamber water air-conditioned motor joined electric dynamometer utilized turning over the motor and estimating the footbrake force created motor. Fig 3.1 demonstrations a diagram sketch CNG DI motor.

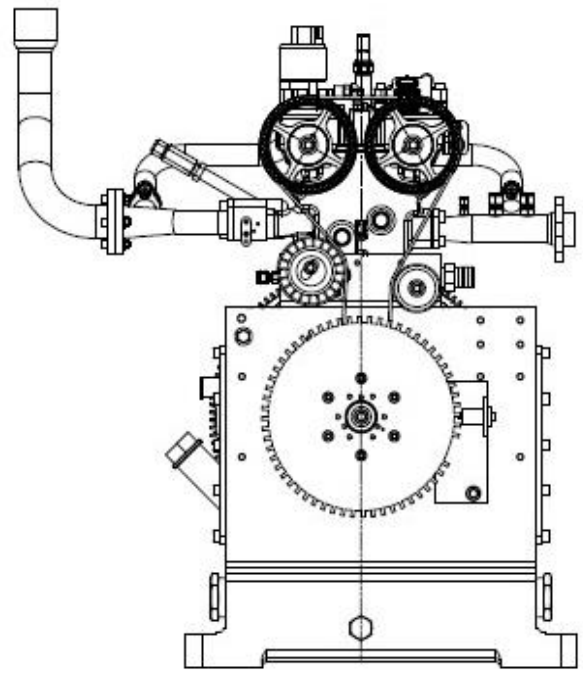

Fig 3.1 The single cylinder CNG DI research engine [38]

\section{Features of the CNG DI Engine}

CNG DI motor essentially intended activity vaporous fills specific consideration regarding activity $\mathrm{CNG}$. The $\mathrm{CNG}$ advanced octane evaluation resources healthier thump obstruction when combusted with sparkle start, the motor has been intended to have a great pressure proportion of 14:1 in order to help flash start and to understand the advantages of higher warm proficiency.

\subsubsection{Gasoline Fuel Injection System}

An extra gas source framework tailored CNG DI motor to work CNG and gas at the same time so the motor might happen the prerequisite of double fuel capacity examination. The fuel was infused complex at an area around $44 \mathrm{~cm}$ admission faucet. The coldness among mark gas 
infusion and admission spigot was reserved long to guarantee same blending of gas and air $[38,39]$. The gas complex infusion includes two frameworks; the essential fuel source framework and an electronics controller framework that is coordinated CNG DI motor.

Table 3.2 Specifications of the gasoline injector.

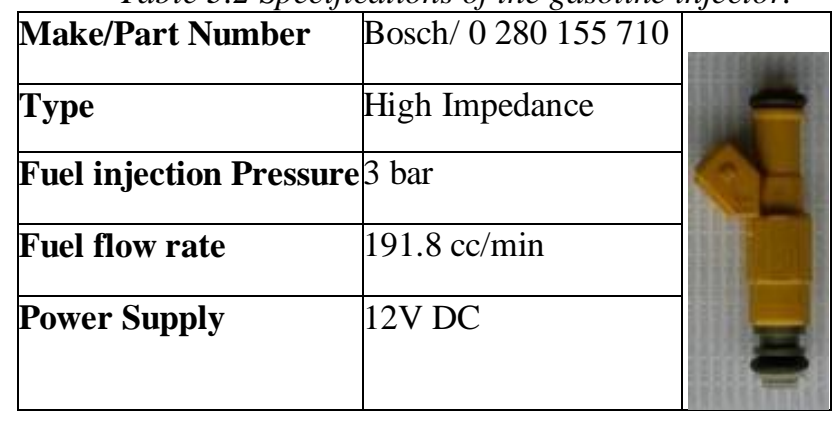

\section{Control of the Gasoline Fuel Injection using LabVIEW}

Fig 3.2 demonstrations the Fig portrayal switch arrangement of infusion. The assignment of regulatory the infusion cycle can be isolated into: ID of TDC, recognizable proof of the force stroke and estimation of wrench point.

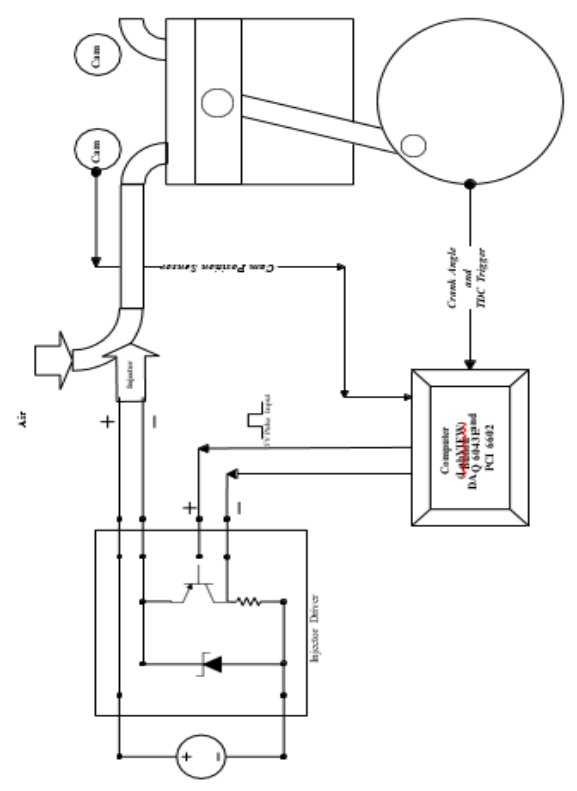

Fig 3.2 LabVIEW based control system of gasoline injection 


\section{Results And Discussion}

The fundamental target of this paper is to consider CNG straight infusion as a device for regulatory $\mathrm{HCCI}$ ignition. Ignition regulator by $\mathrm{CNG}$ shortest infusion can be accomplished utilizing two distinct systems;

\section{Homogeneous blending:}

As CNG has a advanced octane sum gas, its expansion combination an essential fuel (gas) and air resolve bring about a postponement in the start judgment and an increment in the ignition length. Consequently, burning staging constrained by shifting the extent of the CNG into combination. This can accomplished regulatory infusion span CNG and gas.

\section{Variable delineation:}

It is for the most part acknowledged that fuel delineation significantly affects the HCCI burning. Definition of CNG a consistently premixed gas air custody in the chamber can be accomplished finished a mix of CNG direct infusion a uniquely machine channel cylinder top. The level of definition differed altering the CNG infusion judgment.

The two systems were utilized in this examination and their consequences for the presentation of pressure start of CNG and gas air blend are talked about in this part.

\section{Scope of Operable Loads at Different Engine Speeds}

The greatest burden treatable discovered subject equality proportion of fuel and infusion control or level of CNG delineation. The base and greatest burdens treatable deprived of thumping or failure to discharge at all gas comparability proportions and CNG infusion judgments are appeared in Fig 4.1.

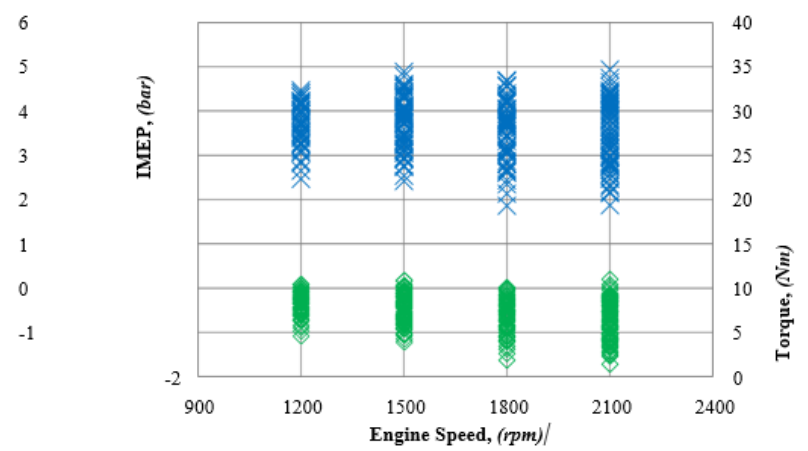

Fig 4.1 Load range operable with dual fuel HCCI combustion 


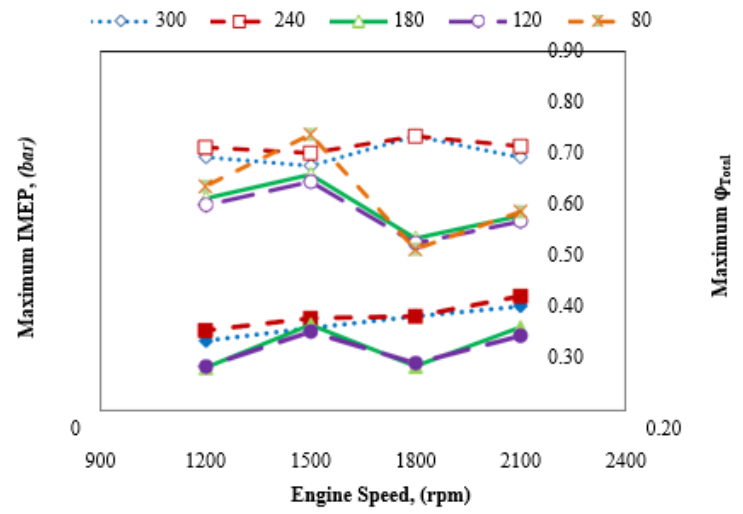

Fig 4.2 Maximum load range obtained at $\varphi_{g}=0.20$.

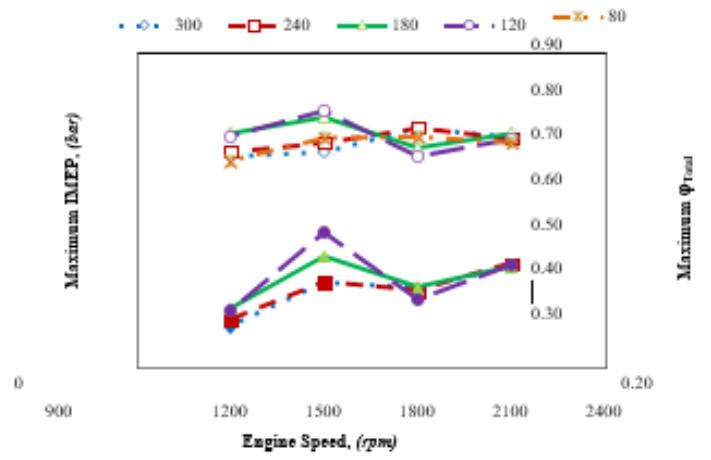

Fig 4.3 Maximum load range obtained at $\varphi_{g}=0.22$.

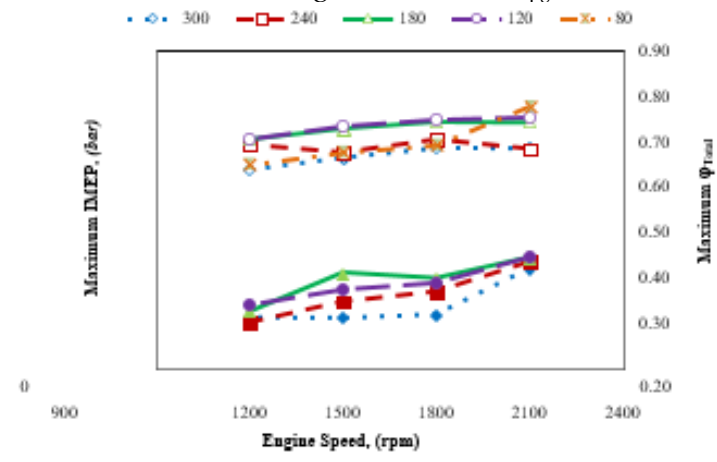

Fig 4.4 Maximum load range obtained at $\varphi g=0.24$. 


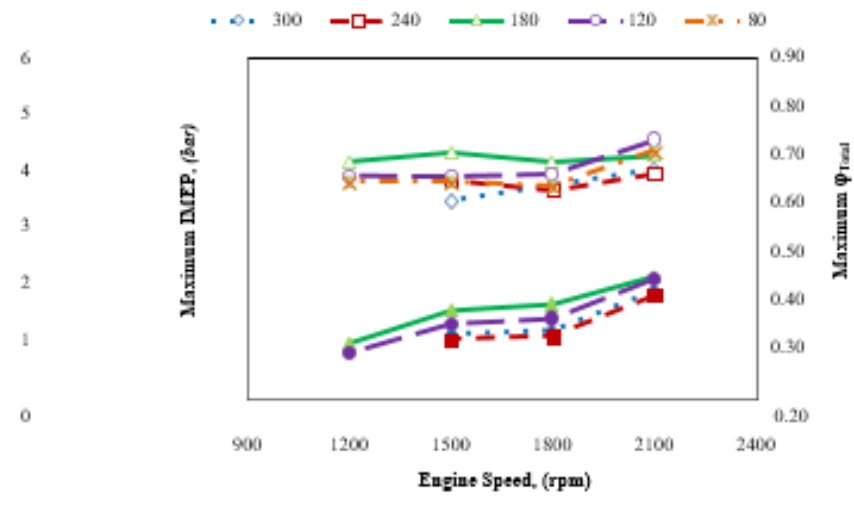

Fig 4.5 Maximum load range obtained at $\varphi_{g}=0.26$.

Likewise, most extreme ,least loads achieved subject to motor speed. The most extreme scope of burdens might be accomplished at $2100 \mathrm{rpm}$ and $1200 \mathrm{rpm}$ curable burden variety restricted.

\section{Overview of Engine Load Range and Operation}

Gas assumes a critical part commencement and attributes of HCCI ignition of a double fuel combination of gas, CNG. As referenced before, there occurs a base equality proportion fuel just exceeding HCCI burning accomplished at admission responsibility temperature $300^{\circ} \mathrm{C}$ driving force of mathematical pressure proportion of $14: 1$. It seen that double fuels activity, the warmth freed ignition of gas was fundamental for the burning of CNG. an intently coordinating with disorder and illustration of Lively Thermo Atmosphere Burning as the thermodynamic air came about because of the HCCI burning of fuel advances the start of CNG and affirmed to writing [40,41]. In this manner, it is imperative to consider the impacts of individual gas equality proportion on the attributes of the double fuel HCCI ignition.

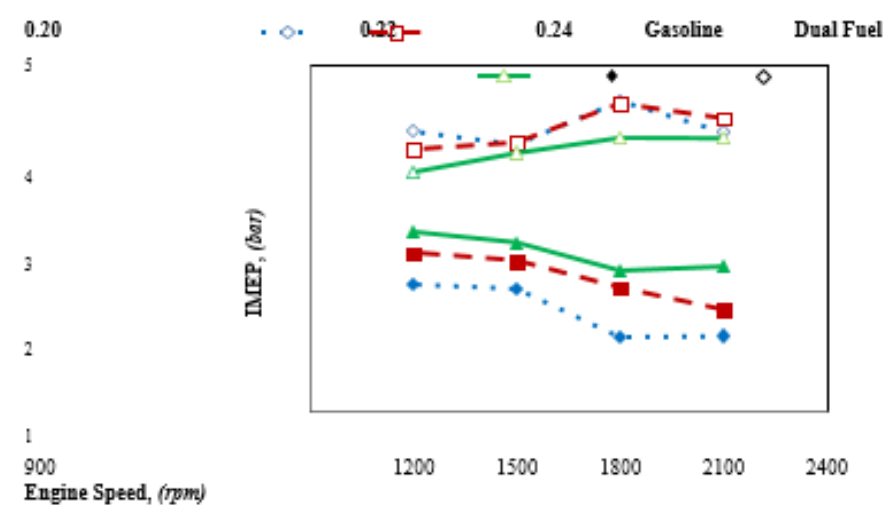

Fig 4.6 Maximum operable load range at dissimilar $\varphi_{g}$ and engine speed at $300^{\circ}$ BTDC. 


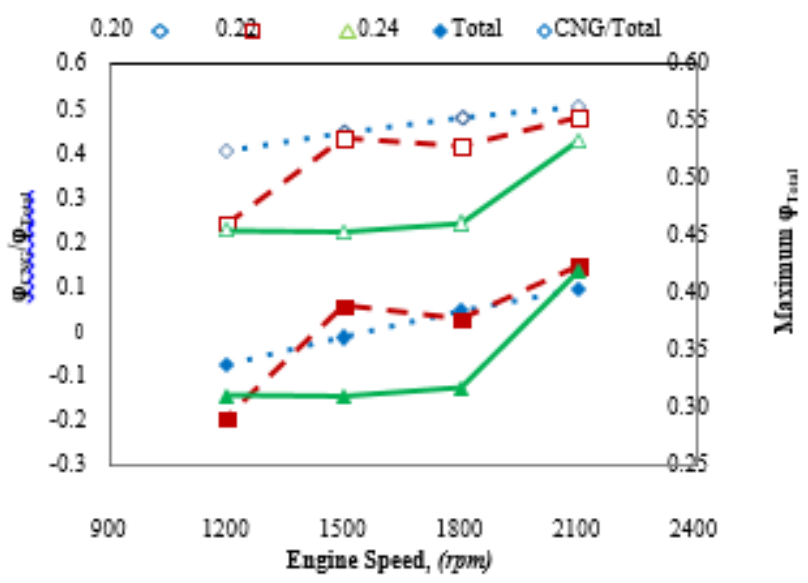

Fig 4.7 Maximum limits of $\varphi_{C N G} / \varphi_{\text {Total }}$ and $\varphi_{\text {Total }}$ at different $\varphi_{g}$ and engine speed at $300^{\circ}$ BTDC.

The greatest burden collection treatable was subject to separate equality proportion gas assumed motor haste. Fig 4.6 demonstrations the most extreme lots that might be worked deprived of thumping, fizzle, or fractional consuming at different fuel equality proportions of $\varphi \mathrm{g}=0.20 ; 0.22$ and 0.24 . At the point when $\mathrm{CNG}$ was infused it expanded the all out identicalness proportion at a steady gas comparability proportion $(\varphi g)$. What's more, the $\varphi g$ was discovered to be a huge factor in characterizing the maximum furthest reaches IMEP possible. Fig 4.6, very well may understood most elevated IMEP was gotten at $1800 \mathrm{rpm}$ practically similar for $\varphi \mathrm{g}=0.20$ and 0.22 velocities.

From Fig 4.7, the most extreme measure of $\mathrm{CNG}(\varphi \mathrm{CNG} / \varphi$ Total) that could be infused was at $\varphi g=0.20$ and $2100 \mathrm{rpm}$. At $2100 \mathrm{rpm}$, the impact of $\varphi g$ on the greatest complete comparability proportion operable was less observable.

It merits recollecting motor speed expanded time span pivot 1 level wrench point $\left(1^{\circ}\right.$ CAD) diminished. thump boundary touchy warmth delivery \& pressing factor increase charges per CAD, activity at higher rates are great for fast ignition, for example, in HCCI burning. $\mathrm{CNG}$

Impacts of Gasoline Equivalence Ratio ( $\varphi \mathrm{g})$ with Homogeneous Mixture of Gasoline and

The ignition of $\mathrm{CNG}$ is started by the warmth delivered by the burning of gas. Subsequently, the measure of fuel present in the general combination fundamentally influences the attributes of the ignition. This segment talks about the impacts of gas stream rates that are addressed as far as proportionality proportion of gas. As the most elevated absolute comparability proportions worked at the motor speeds of $2100 \mathrm{rpm}$, outcomes speed careful examination. 


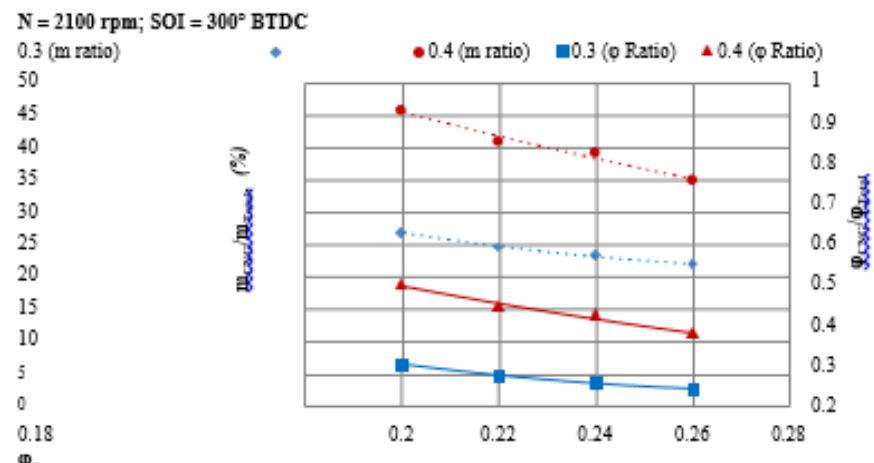

Fig 4.8 The range of $\varphi \mathrm{CNG} / \varphi$ Total and $\mathrm{mCNG} / \mathrm{mTotal}$ at $\varphi$ Total $=0.3$ and 0.4 .

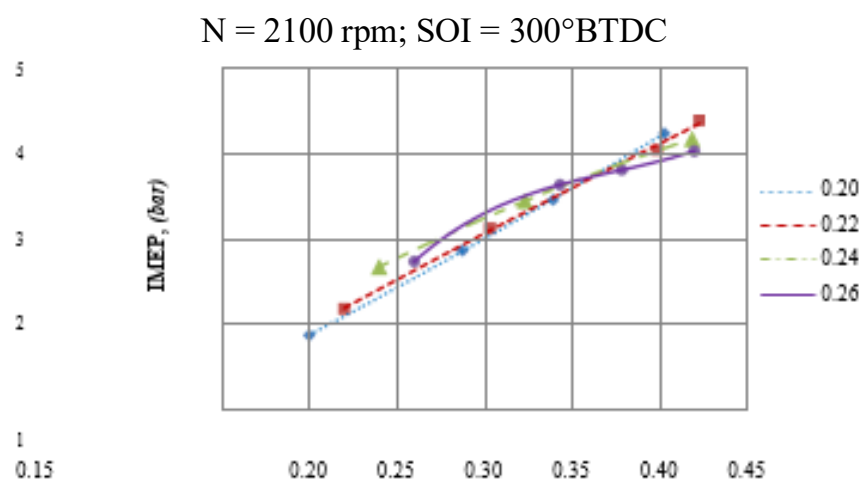

$9 x$ and

Fig 4.9 Effect of $\varphi_{\mathrm{g}}$ on the IMEP obtained at various total equivalence ratios

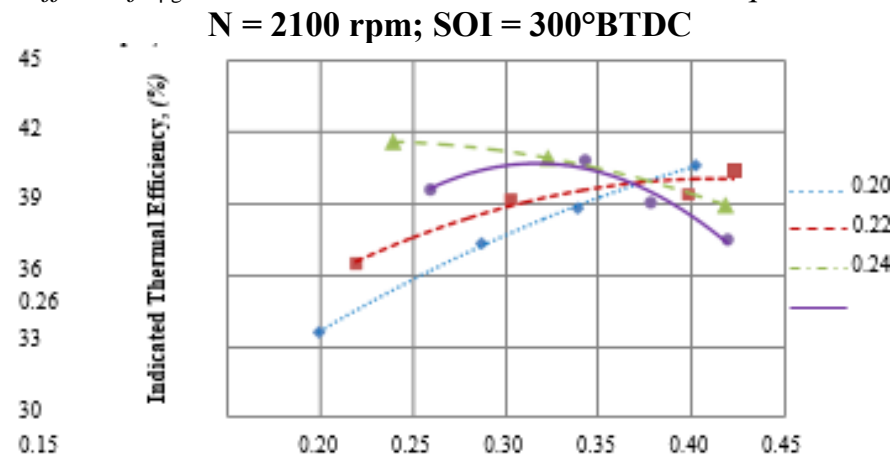

Fig 4.10 Indicated thermal efficiency at different $\varphi_{\mathrm{g}}$

The relating upsides of demonstrated warm effectiveness trail the pattern of IMEP as demonstrated in Fig 4.10. At $\varphi \mathrm{g}=0.20$ and 0.22 , the showed warm effectiveness expanded with an increment in $\mathrm{CNG}$ infusion rate. At $\varphi \mathrm{g}=0.24$, warm productivity diminished 
expansion in $\mathrm{CNG}$ infusion rate. At $\varphi \mathrm{g}=0.26$, warm effectiveness expanded at first yet again diminished at around $\varphi$ Total $=0.32$ because of cutting edge start as exposed Fig 4.11.

$\mathrm{N}=2100 \mathrm{rpm} ; \mathrm{SOI}=\mathbf{3 0 0}{ }^{\circ} \mathrm{BTDC}$

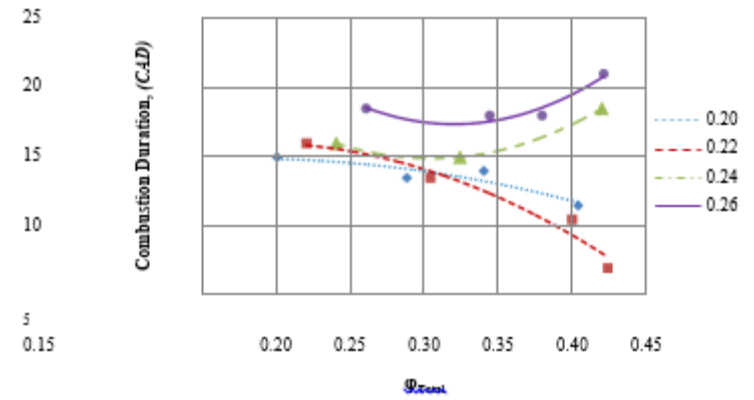

Fig 4.12 Effect of $\varphi_{g}$ and the total equivalence ratio on the combustion duration

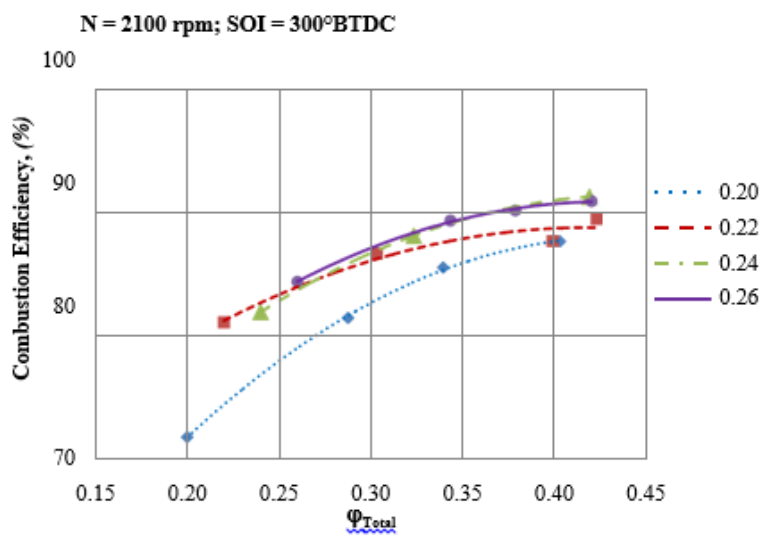

Fig 4.13 Effect of CNG injection rate and $\varphi g$ on combustion efficiency.

Fig 4.13 demonstrations the meaning of gas equality proportion on ignition productivity against complete comparability proportion. With an increment in $\varphi g$, ignition proficiency expanded and the most minimal burning effectiveness was acquired at $\varphi g=0.20$ because of low fuel fixation. At $\varphi g>0.22$, there was a minimal expansion in burning proficiency with an increment in $\varphi \mathrm{g}$. Also, the impact of fuel comparability proportion turned out to be less critical at high upsides of $\varphi$ Total and burning proficiency was more subject to $\varphi$ Total than $\varphi g$ at extraordinary lots and affirmed the discoveries of Cinakr et al. [40], Macuk et al. [47] and Yaoi et al. [43] expansion extent little auto start temperature gasoline recovers the burning productivity great auto start temperature 


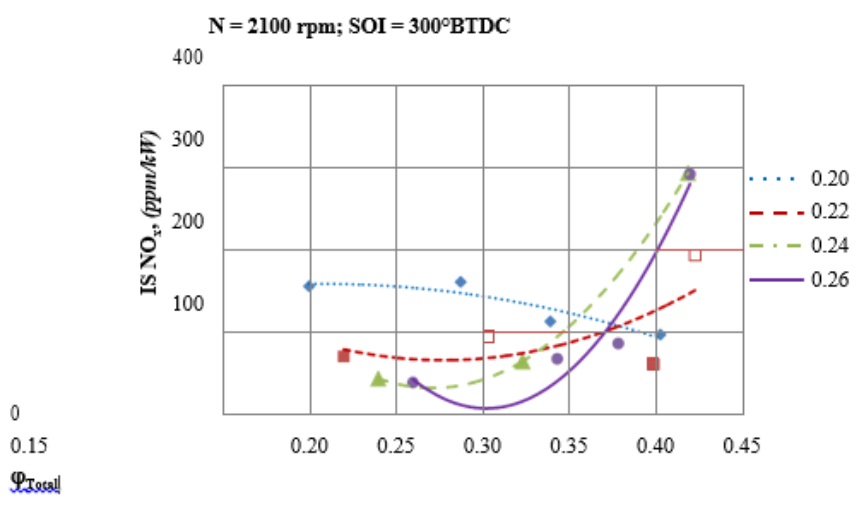

fuel.

Fig 4.14 Effect of CNG injection rate and $\varphi_{g}$ on the NOx emissions.

Fig 4.14 demonstrations NOx outflows expanding CNG infusion degree at different gas equality proportions. At $\varphi g=0.20$, the most noteworthy NOx was noticed, be that as it may, the distinctions were peripheral. Above $\varphi$ Total $=0.40$, NOx discharges would in general increment dramatically, following the common pattern of HCCI $[14,16]$. In any case, the NOx discharges were under $300 \mathrm{ppm} / \mathrm{kW}$ for all cases.

\section{Conclusion and Future work}

The investigation did in this articles needs conversation on the burning marvels like blend arrangement, start spot, and temperatures and pressing factor accounts in the chamber etcetera. Consuming these as a primary concern, an ignition representation education would be more significant. A suggested system for nonstop activity of the motor at ideal state of motor speed and burden while utilizing CNG definition would be helpful. The impact of admission temperature on the burning attributes and outflows with CNG delineation may prompt a superior comprehension of arrangement of NO2 and other temperature delicate toxins.

\section{References}

[1] Alex M.K.P. Taylor, "Science review of Internal Combustion Engines," J. of Energy Policy, vol. 36, pp. 4657-4667, 2008.

[2] L. E. Doman, "International Energy Outlook 2010," U.S. Energy Information Administration, Washington DC DOE/EIA -0484 (2010), July, 2010.

[3] "World Energy Outlook," International Energy Agency, Parice OECD/IEA (2009), 2009.

[4] O. Erlandsson, "Early Swedish Hot-Bulb Engines-Efficiency and Performance Compared to Contemporary Gasoline and Diesel Engines," SAE Paper 2002-01-0115, 2002.

[5] S. Onishi, Hong Jo, S., Shoda, K., Do Jo, P., and Kato, S., "Active thermo- atmosphere combustion (ATAC) - A new combustion process for internal combustion engines," SAE Paper 790507, 1979.

[6] M. Noguchi, Tanaka, Y., Tanaka, T., and Takeuchi, Y., "A study on gasoline engine combustion by observation of intermediate reactive products during combustion," SAE Paper $790840,1979$.

[7] P. M. Najt and D. E. Foster, "Compression-ignited homogeneous charge combustion." vol. SAE Paper 830264, 1983.

[8] R. H. Thring, "Homogeneous-charge compression-ignition (HCCI) engines," SAE Paper 892068, 1989. 
[9] M. Stockinger, Schapertons, H., and Huhlmann, P., "Investigation on a Gasoline Engine Working with Self-Ignition by Compression," MTZ Vole. 53, vol. 2, pp. 80-85, 1992.

[10] H. Zhao, Jian Li., and N. Ladommatos, "Performance and Analysis of a 4- Stroke MultiCylinder Gasoline Engine With Cai Combustion," SAE Paper 2002-01-0420, 2002.

[11] J. Lavy, J. C. Dabadie, C. Angelberger, P. Duret, A. Juretzka, J. Schäflein, T.H. Ma, Y. Lendresse, A. Satre, and C. Schulz, "Innovative ultra-low NOx controlled auto-ignition combustion process for gasoline engines: the 4-space project," SAE Paper 2001-01-1837, 2001.

[12] L. Koopmans and I. Denbratt, "A Four-Stroke Camless Engine, Operated in Homogeneous Charge Compression Ignition Mode With Commercial Gasoline," SAE Paper 2001-01-3610, 2001.

[13] R. H. Stanglmaier and C. E. Roberts, "Homogeneous charge compression ignition (HCCI): benefits, compromises, and future engine applications," SAE Paper 1999-01-3682, 1999.

[14] H. Zhao, HCCI and CAI engines for the automotive industry. Cambridge: Woodhead Publications, 2007.

[15] M. Lida, M. Hayashi, D. E. Foster, and J. K. Martin, "Characteristics of homogeneous charge compression ignition (HCCI) engine operation for variations in compression ratio, speed, and intake temperature while using n- butane as a fuel," Journal of engineering for gas turbines and power, vol. 125, pp. 472 - 478, 2003.

[16] K. Epping, S. M. Aceves, R. L. Bechtold, and J. E. Dec, "The potential of HCCI combustion for high efficiency and low emissions," SAE Paper 2002- 01-1923, 2002.

[17] M. Christensen and B. Johansson, "Influence of mixture quality on homogeneous charge compression ignition," SAE Paper, 982454, 1998.

[18] Z. Zheng and M. Yao, "Numerical simulation of the effects of charge stratification on combustion and emissions," Energy Fuels, vol. 21, pp. 2018- 2026, 2007.

[19] G. S. Jung, Y. H. Sung, B. C. Choi, and M. T. Lim, "Effects of mixture stratification on HCCI combustion of DME in a rapid compression and expansion machine," International Journal of Automotive Technology, vol. 10, pp. 1-7, 2009.

[20] R. Schieß1 and U. Maas, "Analysis of endgas temperature fluctuations in an SI engine by laserinduced fluorescence," Combustion and Flame, vol. 133, pp. 19-27, 2003.

[21] Z. Wang, W. Jian-Xin, S. Shi-Jin, and F. Zhang, "Numerical simulation of HCCI engine with multi-stage gasoline direct injection using 3D-CFD with detailed chemistry," SAE Transactions, vol. 113, pp. 367-380, 2004.

[22] M. Sjoberg, L. O. Edling, T. Eliassen, L. Magnusson, and H. E. Angstrom, "GDI HCCI: Effect of Injection Timing and Air Swirl on Fuel Stratification, Combustion and Emissions Formation," SAE Paper 2002-01-0106, 2002.

[23] C. D. Marriott and R. D. Reitz, "Experimental investigation of direct injection gasoline for premixed compression-ignited combustion-phasing control," SAE Paper 2002-01-0418, 2002.

[24] B. Kim, M. Kaneko, Y. Ikeda, and T. Nakajima, "Detailed spectral analysis of the process of HCCI combustion," Proceedings of the Combustion Institute, vol. 29, pp. 671-677, 2002.

[25] J. Kashdan and G. Bruneaux, "Mixture Preparation and Combustion in an Optically-Accessible HCCI, Diesel Engine," Oil \& Gas Science and Technology, vol. 61, pp. 25-42, 2006.

[26] H. Kim, J. Ryu, and K. Lee, "A study on the characteristics of spray and combustion in a HCCI engine according to various injection angles and timings," Journal of mechanical science and technology, vol. 21, pp. 133- 140, 2007.

[27] Z. Huang, S. Shiga, T.Ueda, H. Nakamura, T. Ishima, T. Obekata, M.Tsue, and M.Kono, "Effect of Fuel Injection Timing Relative to Ignition Timing on the Natural-Gas DirectInjection Combustion," Journal of engineering for gas turbines and power, vol. 125, pp. 783790, 2003.

[28] J. Ma, X. Lu, L. Ji, and Z. Huang, "Evaluation of SCCI potentials in comparison to HCCI and conventional DICI combustion using n-heptane," Energy \& Fuels, vol. 22, pp. 954-960, 2008. 
[29] T. Ishiyama, H. Kawanabe, K. Ohashi, M. Shioji, and S. Nakai, "A study on premixed charge compression ignition combustion of natural gas with direct injection," International Journal of Engine Research, vol. 6, pp. 443-451, 2005.

[30] M. Canakci and R. D. Reitz, "Effect of optimization criteria on direct- injection homogeneous charge compression ignition gasoline engine performance and emissions using fully automated experiments and microgenetic algorithms," Journal of engineering for gas turbines and power, vol. 126, pp. 167 - 178, 2004.

[31] Z. Wang, S. J. Shuai, J. X. Wang, and G. H. Tian, "A computational study of direct injection gasoline HCCI engine with secondary injection," Fuel, vol. 85, pp. 1831-1841, 2006.

[32] Z. Wang, J. X. Wang, S. J. Shuai, G. H. Tian, and X. L. An, "Experimental and computational studies on gasoline HCCI combustion control using injection strategies," Journal of engineering for gas turbines and power, vol. 129, pp. 870-876, 2007.

[33] K. Yoshizawa, A. Teraji, H. Miyakubo, K. Yamaguchi, and T. Urushihara, "Study of high load operation limit expansion for gasoline compression ignition engines," Journal of engineering for gas turbines and power, vol. 128, pp. 377-388, 2006.

[34] K. Lee and C. Lee, "An Experimental Study on the Combustion Characteristics Using the Stratified Charge Compression Ignition in a Direct Injection Gasoline Engine," JSME International Journal, vol. 49, pp. 864- 868, 2006.

[35] C.H. Lee and K. H. Lee, "An experimental study on the combustion and emission characteristics of a stratified charge compression ignition (SCCI) engine," Energy Fuels, vol. 21, pp. 1901-1907, 2007.

[36] J. Chang, Z. S. Filipi, T. W. Kuo, D. N. Assanis, P. M. Najt, and R. B. Rask, "Investigation of Mixture Preparation Effects on Gasoline HCCI Combustion Aided by Measurements of Wall Heat Flux," Journal of engineering for gas turbines and power, vol. 130, pp. 61- 69, 2008.

[37] M. Canakci, "An experimental study for the effects of boost pressure on the performance and exhaust emissions of a DI-HCCI gasoline engine," Fuel, vol. 87, pp. 1503-1514, 2008

[38] D. Law, D. Kemp, J. Allen, G. Kirkpatrick, and T. Copland, "Controlled combustion in an ICengine with a fully variable valve train," SAE Paper 2001-01-0251, 2001.

[39] G. Kontarakis, N. Collings, and T. Ma, "Demonstration of HCCI using a single-cylinder, fourstroke SI engine with modified valve timing," SAE Paper 2000-01-2870, 2000.

[40] C. Cinar, O. Can, F. Sahin, and H. S. Yucesu, "Effects of premixed diethyl ether (DEE) on combustion and exhaust emissions in a HCCI-DI diesel engine," Applied Thermal Engineering, vol. 30, pp. 360-365, 2010.

[41] L. Ji, X. Lu, J. Ma, C. Huang, D. Han, and Z. Huang, "Experimental study on influencing factors of iso-octane thermo-atmosphere combustion in a dual- fuel stratified charge compression ignition (SCCI) engine," Energy \& Fuels, vol. 23, pp. 2405-2412, 2009

[42] Y. Tsutsumi, A. Iijima, K. Yoshida, H. Shoji, and J. T. Lee, "HCCI combustion characteristics during operation on DME and methane fuels," International Journal of Automotive Technology, vol. 10, pp. 645-652, 2009.

[43] M. Yao, Z. Chen, Z. Zheng, B. Zhang, and Y. Xing, "Study on the controlling strategies of homogeneous charge compression ignition combustion with fuel of dimethyl ether and methanol," Fuel, vol. 85, pp. 2046-2056, 2006.

[44] M. Yao, Z. Zheng, and J. Qin, "Experimental study on homogeneous charge compression ignition combustion with fuel of dimethyl ether and natural gas," Journal of engineering for gas turbines and power, vol. 128, pp. 414- 423, 2006.

[45] M. A. Kalam, H. H. Masjuki, M. A. Maleque, M. A. Amalina, H. Abdesselam, and T. M. I. Mahlia, "Air-Fuel Ratio Calculation for a Natural Gas-Fuelled Spark Ignition Engine," SAE Paper 2004-01-0640, 2004.

[46] M. U. Aslam, H. H. Masjuki, M. A. Kalam, H. Abdesselam, T. M. I. Mahlia, and M. A. Amalina, "An experimental investigation of $\mathrm{CNG}$ as an alternative fuel for a retrofitted gasoline vehicle," Fuel, vol. 85, pp. 717-724, 2006. 
[47] J. H. Mack, R. W. Dibble, and D. L. F. B. A. Buchhholz, "The effect of the Di-Tertiary Butyl Peroxide (DTBP) additive on HCCI combustion of fuel blends of ethanol and diethyl ether," SAE Paper 2005-01-2135, 2005.

[48] L. Xingcai, H. Yuchun, Z. Linlin, and H. Zhen, "Experimental study on the auto-ignition and combustion characteristics in the homogeneous charge compression ignition (HCCI) combustion operation with ethanol/n-heptane blend fuels by port injection," Fuel, vol. 85, pp. 2622-2631, 2006 